\title{
BMI open To develop and measure the effectiveness and acceptability of a pharmacy-based chlamydia screening intervention in Australia
}

\author{
Sajni Gudka, ${ }^{1}$ Lewis Marshall, ${ }^{2}$ Alison Creagh, ${ }^{3}$ Rhonda M Clifford ${ }^{1}$
}

To cite: Gudka S, Marshall L, Creagh $A$, et al. To develop and measure the effectiveness and acceptability of a pharmacybased chlamydia screening intervention in Australia. BMJ Open 2013;3:e003338. doi:10.1136/bmjopen-2013003338

- Prepublication history for this paper is available online. To view these files please visit the journal online (http://dx.doi.org/10.1136/ bmjopen-2013-003338)

Received 3 June 2013 Revised 17 July 2013 Accepted 19 July 2013

\section{${ }^{1}$ Centre for Optimisation of Medicines, Pharmacy, School of Medicine and Pharmacology, University of Western Australia, Crawley, Western Australia, Australia ${ }^{2}$ School of Medicine and Pharmacology Medicine, University of Western Australia, Crawley, Western Australia, Australia ${ }^{3}$ Family Planning Western Australia Sexual Health Services, Perth, Western Australia, Australia}

Correspondence to Sajni Gudka;

sajni.gudka@uwa.edu.au

\section{ABSTRACT}

Objectives: To develop and measure the effectiveness and acceptability of a pharmacy-based chlamydia screening intervention called Emergency Contraception Mediated Pharmacy Access to Chlamydia Testing (ECOMPACT).

Design: Selective, opportunistic and cross-sectional study targeting asymptomatic women requesting emergency contraception (EC).

Setting: 20 community pharmacies in the Perth metropolitan region, Australia.

Methods: ECOMAPCT was developed through literature review and stakeholder consensus.

Pharmacists were trained to offer ECOMPACT after the EC consultation. Women with signs and symptoms of sexually transmitted infections (STI) were referred to a physician for a full sexual health check. Asymptomatic women were offered a free ECOMPACT testing kit. The women self-collected a low-vaginal swab and returned their pathological specimen to designated drop-off sites. A pathology service analysed the specimens and sent the results to a sexual health physician. The effectiveness of ECOMPACT was determined by the uptake of the intervention and how well the target population was reached. An effective screening rate was calculated. Qualitative analysis was undertaken to understand acceptability issues from the perspective of the consumer and the pharmacists.

Results: Of the $769 \mathrm{EC}$ consultations in a 6-month period, $569(78 \%)$ women were given information on chlamydia screening. All $247(41 \%)$ agreed to participate. $81(33 \%)$ of these women were ineligible. They were either symptomatic $(n=33 ; 41 \%)$, or were under 18 years of age $(n=48 ; 59 \%)$. Pharmacists successfully requested $166(67 \%)$ pathology tests, of which $46(28 \%)$ were returned to a pathology drop-off site. All tested negative for Chlamydia trachomatis. The effective screening rate was $6 \%$. Consumers and pharmacists considered ECOMPACT to be highly convenient and the time taken to offer a chlamydia test along with an EC consultation as highly appropriate.

Conclusions: ECOMPACT was found to be simple, effective and acceptable. Given the opportunity, adequate training and support, community pharmacists in Australia were capable of requesting direct-toconsumer chlamydia tests.

\section{ARTICLE SUMMARY}

Article focus

- We propose that all women requesting emergency contraception (EC), including those obtaining it from community pharmacies, should have the opportunity to be tested for chlamydia.

- We developed and measured the effectiveness and acceptability of a pharmacy-based chlamydia screening intervention. It was called Emergency Contraception Mediated Pharmacy Access to Chlamydia Testing (ECOMPACT).

Key messages

- We determined that the ECOMPACT model was effective and acceptable.

- The ECOMPACT model enabled community pharmacists to screen consumers, identify and refer those who were symptomatic and request a pathology chlamydia test for those who were not.

- Given the opportunity, adequate training and support, community pharmacists in Australia are capable of requesting direct-to-consumer chlamydia tests.

Strengths and limitations of this study

- ECOMPACT was an extension to the pharmacists' EC consultation; therefore, it was implemented with minimal changes to the existing workflow.

- Two types of selection bias were identifiedpharmacists introduced selection bias by not offering the ECOMPACT intervention to all EC consumers, while consumers introduced selfselection bias by deciding whether they wanted to participate or not.

- Ethical constraints prevented us from following up the 33 women who were found to be symptomatic of a sexually transmitted infection; therefore, we may have underestimated the full effectiveness of the ECOMPACT model.

\section{INTRODUCTION}

Chlamydia, caused by the bacterium Chlamydia trachomatis, is one of the most common bacterial sexually transmitted infections (STI) in developed countries. ${ }^{1}$ It is also 
the most frequently notified STI in Australia. ${ }^{2}$ In 2011, 80824 new cases of chlamydia were reported, equating to a rate of $362 / 100000$ population. ${ }^{3}$ This represented a $9 \%$ increase from the rate reported in 2010 of 332/ 100000 population. ${ }^{3}$

Control of chlamydia is challenging because the majority of people infected are asymptomatic. ${ }^{4}$ Unless an infected individual presents for a health check or is alerted by a sexual partner who has developed symptoms, he/she may remain infectious, yet asymptomatic, for a long time. ${ }^{4-6}$ Left untreated, persistent chlamydia can result in serious sequelae including pelvic inflammatory disease, ectopic pregnancy and tubal infertility in women and epididymitis and epididymo-orchitis in men. ${ }^{4-7}$ These complications cause considerable distress to the individuals and, in the case of infertility, can have major cost implications for health services if interventions such as tubal surgery and in vitro fertilisation are required. ${ }^{5}$

Even though Australian national guidelines recommend that general practitioners (GPs) test all sexually active people aged $15-25$ years annually for chlamydia, ${ }^{8}$ a retrospective evaluation for the period from October 2007 to September 2008 indicated that only $8.9 \%$ (95\% CI $8.88 \%$ to $8.94 \%$ ) of young people who visited their GP had been tested. ${ }^{9}$ In addition, research has found that the high costs associated with getting tested, long waiting times at clinics, inconvenience, fear of medical procedures, stigma associated with STIs and lack of privacy prevent some young people from accessing chlamydia screening through their GP. ${ }^{10-12}$ To overcome these barriers and increase the number of young people being tested annually for chlamydia in Australia, it seems apt to consider alternative venues which young people would find convenient and where they would feel at ease while getting a chlamydia test. One such location could be a community pharmacy.

There is a gathering body of evidence to suggest that community pharmacies could contribute to the overall goal of increasing chlamydia testing. ${ }^{13}{ }^{14}$ In England, most community pharmacies provide free chlamydia tests to young people under the age of 25 years as part of the National Chlamydia Screening Program. ${ }^{15} 16$ In addition, some pharmacies sell chlamydia testing kits over the counter. ${ }^{13}$ Evaluations of these interventions have shown that the typical attributes of a community pharmacy, such as location, long evening and weekend opening hours and supervision by a regulated primary healthcare provider, are rated highly by consumers. ${ }^{13} 14 \quad 17 \quad 18$ These findings were reiterated in a recently published systematic review on pharmacy-based chlamydia screening intervention. ${ }^{14}$ Here the authors concluded that community pharmacies provided young people with an easily accessible and convenient alternative to obtain a chlamydia test. ${ }^{14}$ This review also found that pharmacists and consumers agreed that the offer of a chlamydial test during a sexual health consultation, such as EC, was highly appropriate. ${ }^{14}$
A recently published study of women requesting EC from community pharmacies in Australia found that all the 113 women surveyed were at risk of chlamydia. ${ }^{19}$ All of them reported the inconsistent use of barrier contraception, $85 \%$ were between 16-29 years of age and $56 \%$ had more than one sexual partner in the previous 12 months. ${ }^{19}$ While the availability of EC from a community pharmacy had given them timely and convenient access to $\mathrm{EC},{ }^{20}$ there was no opportunity of being tested for chlamydia, thus unwittingly increasing their risk of carrying chlamydia undetected. ${ }^{19}$

It is this gap in the provision of sexual health services for EC consumers that is the focus of our research. We believe there is an urgent need to supplement current sexual health services in Australia so that all EC consumers-including those obtaining EC from pharmacieshave the opportunity to be tested for chlamydia. The aim of this study was to develop and measure the effectiveness and acceptability of a pharmacy-based chlamydia screening intervention in Australia that targets women requesting EC.

\section{METHODS}

The study was approved by the Human Research Ethics Committee of the University of Western Australia. All participating pharmacists and consumers provided their written consent. The methodology of the ECOMPACT intervention (table 1) is explained in detail elsewhere. ${ }^{21}$ Briefly, the features were:

Study design: Selective, opportunistic, cross-sectional study targeting asymptomatic women requesting EC from 20 pharmacies in the Perth metropolitan region.

Pharmacy recruitment: Invitations to participate in the study were sent to all 401 pharmacies in the Perth metropolitan region. The first 20 pharmacies that expressed interest, had a private consultation/screened area and had an average of $\geq 8 \mathrm{EC}$ requests per month were sent further information about the study protocol together with details of the compulsory $2 \mathrm{~h}$ training course.

Consumer recruitment: After EC consultations, pharmacists introduced the consumers to the pharmacy-based chlamydia screening study, discussed the risks of STIs, obtained consent for participation or recorded their reasons for non-participation. Participating women filled in an eligibility assessment form requesting them to state their age and to complete a checklist of symptoms of STIs.

Consumer exclusion criteria: Women with symptoms suggestive of STIs (dysuria, pain during/after sex, unusual vaginal discharge, lower abdominal pain and abnormal bleeding) were excluded, as the objective of the screening was to identify asymptomatic infected individuals. Symptomatic women were immediately referred to their GP or a sexual health clinic for a sexual health check. Women under the age of 18 years were also excluded because they were under the age of consent for the study. They were, however, strongly encouraged to 
Table 1 Emergency Contraception Mediated Pharmacy Access of Chlamydia Testing Intervention (ECOMPACT)

\begin{tabular}{|c|c|}
\hline Study design & $\begin{array}{l}\text { Selective, opportunistic cross-sectional study from } 20 \text { pharmacies in the Perth } \\
\text { metropolitan region }\end{array}$ \\
\hline Eligibility criteria & Asymptomatic women $\geq 18$ years requesting EC \\
\hline Specimen type and collection method & $\begin{array}{l}\text { Self-collected low-vaginal collection swab taken either at home or at a } \\
\text { designated pathology laboratory }\end{array}$ \\
\hline Options for returning specimen for analysis & $\begin{array}{l}\text { Either at one of the designated pathology laboratories or at the primary issuing } \\
\text { pharmacy }\end{array}$ \\
\hline Pathology laboratory procedure & $\begin{array}{l}\text { Nucleic acid amplification tests utilising target capture, transcription-mediated } \\
\text { amplification and hybridisation protection assay }\end{array}$ \\
\hline $\begin{array}{l}\text { Dissemination of chlamydia test results to } \\
\text { consumers }\end{array}$ & $\begin{array}{l}\text { Designated free-phone number that women called } 72 \mathrm{~h} \text { after returning their } \\
\text { specimen. Results handled by a chlamydia screening officer based at Sexual } \\
\text { Health Services, Fremantle Hospital }\end{array}$ \\
\hline $\begin{array}{l}\text { Treatment for chlamydia positive women } \\
\text { and sexual partner notification }\end{array}$ & $\begin{array}{l}\text { Handled by a sexual health physician based at Sexual Health Services, } \\
\text { Fremantle Hospital }\end{array}$ \\
\hline
\end{tabular}

request a chlamydia test from their GP or a sexual health clinic.

Issuing of chlamydia test: The pharmacist assigned a unique four-digit patient identification code to each eligible woman, completed a pathology request form and issued a free ECOMPACT testing kit. The ECOMPACT testing kit, packaged in a discreet plain white envelope, consisted of a GEN-PROBE APTIMA unisex low-vaginal collection swab; a GEN-PROBE APTIMA swab transport medium tube; a biohazard bag; a leaflet with detailed instructions on the study protocol, how to collect and transport the specimen and a wallet-sized reminder card with details on how to obtain their test results.

Specimen type and pathology process: The women selfcollected a low-vaginal swab either at home or at one of the designated pathology laboratories. They were responsible for returning their pathology specimen to a pathology laboratory or to the pharmacy that issued the test. The specimens were analysed using nucleic acid amplification tests utilising target capture, transcriptionmediated amplification and hybridisation protection assays. The GEN-PROBE APTIMA sensitivity and specificity of a self-collected low vaginal swab were 96.6 and 97.4, respectively.

Financial incentives: Two different types of financial incentives were given to the 20 participating pharmacies. An initial \$A1000 was provided to each pharmacy to aid the implementation of the study protocol and cover expenses incurred in upskilling their staff in chlamydia screening. In addition, each pharmacy received \$A15 for every chlamydia test issued by the pharmacy that was completed and returned for testing. There was no consumer participation incentive.

Intervention timeframe: The intervention took place over a period of 6-months, from July 2009 to December 2009.

\section{Data collection}

To determine the effectiveness of the study, the extent to which ECOMPACT operated and how well the target population was reached were measured. The number of EC consultations, number invited to participate, number who accepted, number who refused and number who completed the chlamydia test were recorded. To measure how well the target population was reached, the effective screening rate (ESR) was calculated as the total number who completed chlamydia test/total number of EC consultations was calculated.

A combination of Computer Assisted Telephone Interviews (CATI) and focus groups was used to obtain consumer level factors. These included demographics, acceptability and barriers to ECOMPACT and reasons for non-participation. Focus groups were also utilised to explore the pharmacy level factors such as pharmacists' attitudes, facilitators and barriers during implementation and delivery of ECOMPACT.

The CATI questionnaire was developed, piloted on five female pharmacy students and revised accordingly. The final questionnaire consisted of 34 questions in three sections. The first section gathered information on the participant's demographics and their contraceptive practices. The second section contained five-point Likert-scale questions (with a central neutral response) to determine their satisfaction during the different stages of their participation in ECOMPACT and their willingness to pay for a similar service in the future. The final section contained open-ended questions in which they could further explain any facilitators and/or barriers they had experienced.

An interactive Microsoft Access Database was developed and customised for the CATI questionnaire. To maintain consistency in the interview and the data entry process, a research assistant experienced with the CATI process was employed to conduct all the interviews. Consumers who had consented (and supplied their phone number) to participate in the CATI questionnaire were contacted 3-6 weeks after taking the ECOMPACT Testing Kit home.

In addition, all consumers and pharmacists who provided consent to participate in focus groups were invited to their respective focus group. The themes of the focus group were broad, with open-ended questions aimed at exploring attitudes, events, facilitators and barriers 
experienced during ECOMPACT. To maintain consistency between the consumer and pharmacist focus groups, an experienced external facilitator was appointed to conduct them. Two moderators were also employed to observe the groups independently. The focus group sessions were audio recorded and transcribed verbatim.

\section{Statistical analysis}

For quantitative data, statistical analysis was carried out using SPSS V.17.0. Age was normally distributed and hence is reported as mean \pm sd. Student's t test was used to compare the mean age. Fisher's exact test was used to compare all categorical variables. Significance was set at the $5 \%$ level. The proportion of respondents who were willing to pay and the overall mean $\pm \mathrm{SD}$ of their monetary figure were calculated.

Information from the open-ended questions in the CATI questionnaire and the digital audio recordings from the focus group was transcribed verbatim. Two independent researchers manually coded, thematically analysed and interpreted the data. Discrepancies were discussed and resolved in collaboration with a third researcher.

\section{RESULTS}

Of the $769 \mathrm{EC}$ consultations recorded, $596(78 \%)$ were offered ECOMPACT. 247 (41\%) agreed to participate. 81 $(33 \%)$ of these women were ineligible either because they reported symptoms of STIs $(n=33 ; 41 \%)$ or they were under 18 years of age $(n=48 ; 59 \%)$. The remaining 166 $(67 \%)$ eligible and asymptomatic women were issued an ECOMPACT testing kit. $46(28 \%)$ of these women returned the completed test to pathology, of which all tested negative for $C$ trachomatis. The return rate of the study was $28 \%$ and the ESR was $6 \%$ (figure 1).

Non-participation was measured at two points-at the pharmacy-level $(n=349)$ and after taking the ECOMPACT kit home $(n=120)$. Pharmacists recorded pharmacy-level non-participation in only 65 of the 349 (19\%) womenthe most common reasons were being married/in a stable relationship $(\mathrm{n}=37 ; 57 \%)$ and having had an STI test in the last 4 weeks $(\mathrm{n}=22 ; 34 \%)$. Reasons for non-participation after taking the ECOMPACT testing kit home were obtained for 71 of the $120(60 \%)$ women in the CATI survey. They were: inconvenience of taking the test to a designated pathology/pharmacy drop-off site $(n=19 ; 27 \%)$; self-assessment of not being at risk of chlamydia $(\mathrm{n}=17$, $24 \%)$; tested at the GP instead ( $\mathrm{n}=16$; $23 \%)$; lost the chlamydia testing kit $(\mathrm{n}=13,18 \%)$; assumed the test had expired $(\mathrm{n}=3,4 \%)$ and assumed the study period was over and therefore had binned the testing kit $(n=3,4 \%)$.

Of the 166 women who took the ECOMPACT testing kit home, 91 (55\%) women completed the CATI questionnaire. Table 2 shows that there were no statistical differences in the consumer's age, occupation status, qualifications and usual methods of contraception between the $\mathrm{n}=20$ women who completed the chlamydia test and the $\mathrm{n}=71$ women who did not. However, significantly more women returned the test $(p=0.04)$ if they felt they had been provided enough information about the pharmacy-based chlamydia screening study by the pharmacist.

In the CATI open-ended questions, the women responded that the key strengths of ECOMPACT were 'highly convenient, raised awareness of chlamydia, and provided them with a confidential venue that did not

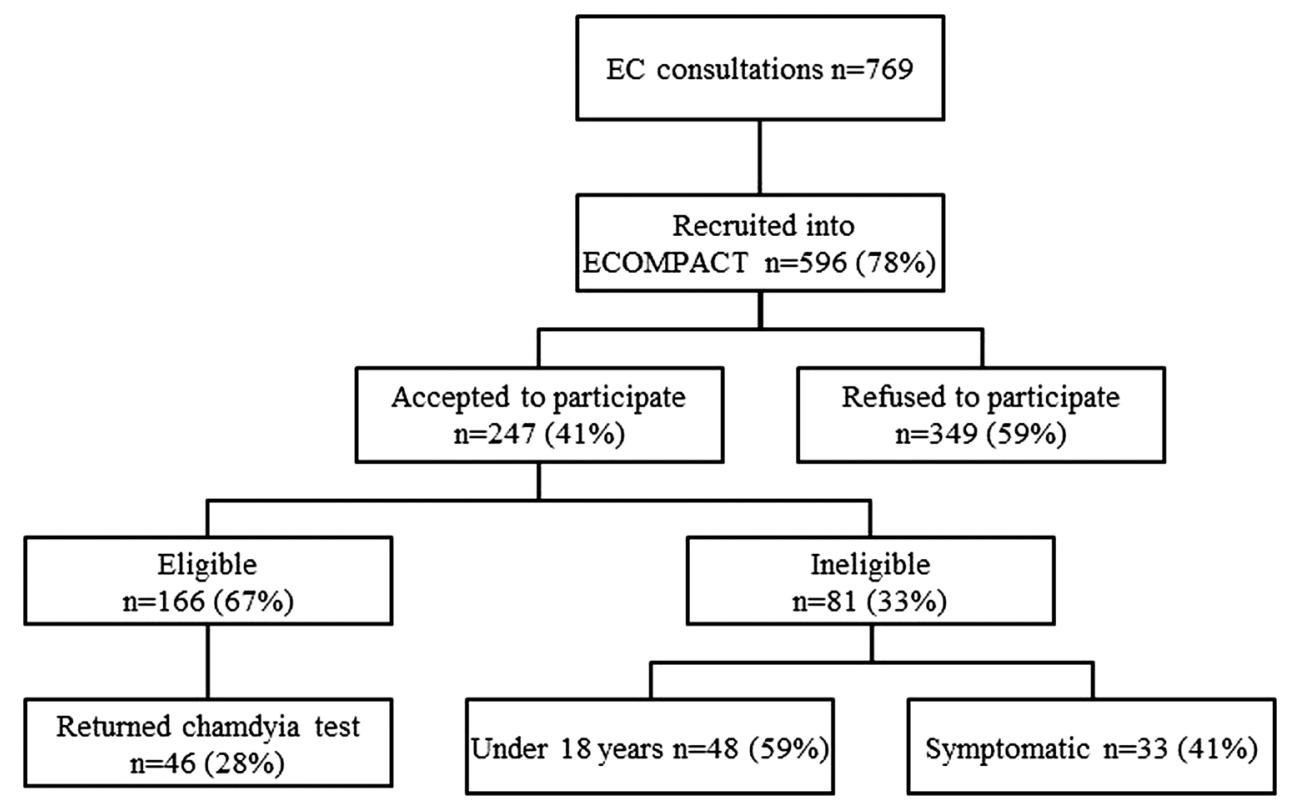

Figure 1 Participating at different stages of Emergency Contraception Mediated Pharmacy Access to Chlamydia (ECOMPACT) protocol. Recruitment rate: $596 / 769=78 \%$; acceptance rate: $247 / 596=41 \%$; return rate: $46 / 166=28 \%$; effective screening rate: 46 / $769=6 \%$. 
Table 2 Results of the CATI questionnaire $(n=91)$

\begin{tabular}{|c|c|c|c|}
\hline & $\begin{array}{l}\text { Returned test } \\
n=20(\%)\end{array}$ & $\begin{array}{l}\text { Did not return test } \\
n=71(\%)\end{array}$ & p Value \\
\hline Mean age $\pm S D$ years & $25.2 \pm 5.5$ & $23.8 \pm 4.8$ & 0.27 \\
\hline \multicolumn{4}{|l|}{ Occupation status } \\
\hline Student & $5(25)$ & $17(24)$ & 1.00 \\
\hline Working part-time/full-time & $14(56)$ & $47(66)$ & 1.00 \\
\hline Other & $1(5)$ & 7 (10) & 0.68 \\
\hline \multicolumn{4}{|l|}{ Qualifications } \\
\hline Up to year 12/equivalent & $4(20)$ & $25(35)$ & 0.28 \\
\hline TAFE & $10(50)$ & $22(31)$ & 0.18 \\
\hline University degree & $6(30)$ & $24(34)$ & 1.00 \\
\hline \multicolumn{4}{|l|}{ STI test in last 12 months } \\
\hline Yes & $6(30)$ & $34(48)$ & 0.20 \\
\hline \multicolumn{4}{|l|}{ Usual method of contraception* } \\
\hline Condoms & $11(55)$ & $41(58)$ & 1.00 \\
\hline Oral contraceptives & $10(50)$ & $36(51)$ & 1.00 \\
\hline Other & $2(10)$ & $5(7)$ & 0.65 \\
\hline None & $1(5)$ & $6(8)$ & 1.00 \\
\hline \multicolumn{4}{|c|}{ Did the pharmacist provide enough information on the chlamydia screening study? } \\
\hline Yes & $19(95)$ & $51(72)$ & 0.04 \\
\hline \multicolumn{4}{|c|}{ Was the pharmacy consultation confidential? } \\
\hline Yes & $18(90)$ & $53(75)$ & 0.22 \\
\hline
\end{tabular}

require a pre-planned appointment with a health professional'. They suggested that improvements to the protocol should 'ensure all the pharmacies have, and utilise, a private consultation area, increase pharmacist knowledge, skills and communication, increase the number of sites where the completed test can be returned, and raise public awareness of ECOMPACT.' Finally, 28 (30\%) women said they would be willing to pay $\$ A 26 \pm 9$ for a chlamydia test from a pharmacy.

The key findings of the consumer $(n=5)$ and pharmacist $(n=6)$ focus groups are shown in table 3. Overall, the consumers said that women should have more access to sexual health services and that a 'community pharmacist is an appropriate professional' to start providing chlamydia screening services. They acknowledged that offering chlamydia screening with EG was an ideal opportunity to screen women, 'that it was not personal, but because they had unprotected sex, it was a responsible approach and entirely the right timing.'

When consumers were asked a polar (yes/no) CATI question to indicate whether they were concerned about privacy, $83 \%$ answered that they were not concerned. However, of the same consumers, in the open-ended CATI questions, almost $50 \%$ of them said they experienced a lack of privacy. In the focus group, the consumers said that a dedicated private consultation area was preferable and that they would not feel comfortable discussing sexual health 'over the counter'.

The pharmacists stated that their overall experience with ECOMPACT was very positive. They all recognised its importance and said it gave them an opportunity to participate in public health initiatives in sexual health. While they felt confident and comfortable talking about EC and chlamydia screening with women, they would prefer having more STI knowledge and private consultation areas to enhance interactions with the consumers.

\section{DISCUSSION}

Principal findings

This was the first study of pharmacy-based chlamydia screening in Australia to focus on women requesting EC. The study proved that the ECOMPACT model was effective and acceptable. Consumers and pharmacists considered the service to be highly convenient, and the timing of offering a chlamydia test with an EC consultation as highly appropriate. However, the study also showed that the ECOMPACT model could be improved by increasing the pharmacists' skill in consulting with consumers and providing more options for consumers to return their completed chlamydia tests.

\section{Strengths and limitations}

The primary strength of our study was its use of existing infrastructure in community pharmacies. Since the service was an extension to EC consultations that were already part of the pharmacies' service schedule, it was implemented with minimal changes to the existing workflow. The ECOMPACT model enabled community pharmacists to screen consumers, identify and refer those who were symptomatic and to request a pathology chlamydia test for those who were not. All tests returned to 
Table 3 Key findings from the consumers' and pharmacists' focus groups

\begin{tabular}{|c|c|}
\hline Key findings from the consu & focus group $(n=5)$ \\
\hline Approach by a pharmacist & $\begin{array}{l}\text { As there was no prior advertisement of the study, all consumers were } \\
\text { all spoke about being 'surprised' when the pharmacist introduced ECC } \\
\text { agreed that the initial 'surprise' subsided fairly quickly because the ph } \\
\text { the consultation professionally }\end{array}$ \\
\hline $\begin{array}{l}\text { Confidentiality/environment of } \\
\text { pharmacy }\end{array}$ & $\begin{array}{l}\text { All five consumers had different experiences about privacy and confid } \\
\text { consultation with the pharmacist. Two consumers had their consultatic } \\
\text { counter in the pharmacy with very little or no privacy }\end{array}$ \\
\hline ECOMPACT testing kit & $\begin{array}{l}\text { They found the written material and instructions well set out, self-expla } \\
\text { read and understand. Self-collection of LVS was easy to use and was }\end{array}$ \\
\hline Returning the specimen & $\begin{array}{l}\text { Two consumers said that returning the pathology sample to the desig } \\
\text { their biggest deterrent. Had this process been simpler or more conver } \\
\text { have completed the process }\end{array}$ \\
\hline Obtaining results & $\begin{array}{l}\text { While calling a designated phone number to obtain their test results } \mathrm{w} \\
\text { methods such as postal mail and email should also have been provid }\end{array}$ \\
\hline $\begin{array}{l}\text { Strategies for improving for } \\
\text { ECOMPACT }\end{array}$ & $\begin{array}{l}\text { 1. Ensure all pharmacies have and use separate consultation areas } \\
\text { 2. Make chlamydia testing available at all times from all pharmacies } \\
\text { 3. Advertise pharmacy chlamydia testing service } \\
\text { 4. Education on chlamydia screening to pharmacist and consumers } \\
\text { 5. Package EC and chlamydia kit together } \\
\text { 6. Increase venues for returning completed specimen } \\
\text { 7. Consider using postal returns for completed specimen } \\
\text { 8. Give multiple options for obtaining results-mail/email/phone }\end{array}$ \\
\hline
\end{tabular}

Key findings from the pharmacist focus group $(n=6)$

Engaging with the EC consumer Pharmacists said they felt confident and comfortable talking about EC and chlamydia testing. They found recruiting women for ECOMPACT difficult because women did not want to spend time in the pharmacy or were not interested in chlamydia screening.

Infrastructure (time, paperwork and money) They all agreed that the paperwork and documentation took extra time. EC was usually requested on weekends and evenings. This allowed some of the quieter pharmacies to spend time with the consumer, while those that had locum pharmacists on weekends found ECOMPACT very time-consuming and difficult to implement.

Strategies for improving for ECOMPACT

- Simplify the paperwork or incorporate into PSA EC checklist

- Utilise a web-based system for recording

- Provide adequate compensation/incentives for time

- Provide ongoing training on chlamydia and communication skills

- Make chlamydia testing available at all times from all pharmacies

EC, emergency contraception; ECOMPACT, Emergency Contraception Mediated Pharmacy Access to Chlamydia Testing; LVS, low vaginal swab; PSA, Pharmaceutical Society of Australia.

pathology centres were analysed and the results were disseminated without complications. This indicates that the infrastructure and procedures set out by the research team were well founded and that, given the opportunity, adequate training and support, community pharmacists in Australia were capable of requesting direct-toconsumer chlamydia tests.

Some aspects of the ECOMPACT model remained untested. Ethical constraints prevented us from offering ECOMPACT to consumers aged 16-18 years. It also prevented us from following up the outcomes of referrals of symptomatic consumers. Without knowing if any of these were positive and thus if a successful intervention had been made, we may have underestimated the potential effectiveness of the true potential of pharmacists' role in chlamydia screening.

The final component of ECOMPACT, treatment for chlamydia-positive women and partner notification, remained untested. This is because all 46 returned tests tested negative for chlamydia. An Australian prevalence survey of 657 asymptomatic women $(n=657)$ found that women of similar age (women aged 18-29 years) and demographics as ECOMPACT had an overall chlamydia prevalence of $0.9 \% .^{22}$ Other Australian prediction models for the prevalence of chlamydia suggest that it ranges from $0.5 \%$ to $3.5 \%$ and is dependent on the demographics of those tested and their associated sexual risk factors. ${ }^{23}{ }^{24}$ Accordingly, the findings of this feasibility study were consistent with the published figures.

Another limitation that we encountered was selection bias. Not all EC consumers were recruited in the ECOMPACT intervention, which is evident in the balance of the number of women requesting $\mathrm{EC}$ and the recorded number of ECOMPACT interventions offered. Selection bias by the pharmacists may have led to ECOMPACT not being offered to some consumers 
because they were judged to be at low risk or because the pharmacist felt uncomfortable or lacked the skill to approach the subject of sexual health. ECOMPACT may also not have been offered when the pharmacy was too busy at the time of the consultation. In addition, consumer self-selection bias may have occurred because women were given a choice of whether they wanted to participate or not. Some women who did not perceive themselves at risk may have refused to take the kit, while others felt obliged to take it anyway, with no intention of using it.

\section{ECOMPACT in relation to other studies}

We compared the effectiveness of ECOMPACT against equivalent data from other opportunistic studies, ${ }^{25-27}$ where pharmacists offered the test to a selected cohort of consumers as well as population-based studies, ${ }^{18} 2829$ where eligible consumers could request a chlamydia test from the pharmacies. Population-based studies generally had higher return rates ranging from $58 \%$ to $68 \%$ than opportunistic studies with return rates ranging from $12 \%$ to $27 \% .^{18}{ }^{25-29}$ This was primarily because the initiative to request a test in population-based studies lay with the consumer, who would typically only request a test if they perceived themselves to be at risk of chlamydia in some way. Consequently, their motivation to complete the test was higher than that of consumers who had been offered a test opportunistically. The highest return rate of $68 \%$ in the Canberra study was achieved by awarding $\$ A 10$ cash for a returned sample. ${ }^{29}$ This type of consumer incentive is not normally sustainable or replicable in public health initiatives.

The return rate of $28 \%$ in the ECOMPACT study was marginally higher than those in the other three opportunistic pharmacy-based chlamydia-screening studies published until now. ${ }^{25-27}$ Of these, only Van Bergen et $a l^{27}$ reported sufficient uptake data to calculate an ESR, which was $20 \%$ compared to our $6 \%$. The key difference between their study and our study was that it was conducted from one pharmacy healthcare centre. The toilet facilities within the health centre allowed women to complete the test on-site and return it to the pharmacy immediately. ECOMPACT encouraged home-based testing, and the initiative to return the test to a pathology centre was with the consumer. Outside a pharmacy setting, we noted that a retrospective evaluation of chlamydia-screening studies conducted from GPs in Australia showed an ESR of $6.3 \%$ for women and 1.6\% for men. ${ }^{9}$ Therefore, these comparisons indicate that while some of the findings of ECOMPACT fall short of the high benchmarks set by well-funded and marketed population-based pharmacy screening programmes, they are comparable to other successful opportunistic pharmacy and GP-based chlamydia screening studies.

To determine the factors that would limit the uptake of ECOMPACT in the pharmacy, pharmacists had been instructed to record reasons for non-participation. The data showed that women refused to accept ECOMPACT when they perceived themselves to be at low risk either because they were married/in a stable relationship or had recently been tested for chlamydia. These findings concur with the commonly cited reasons for refusing chlamydia tests in other pharmacies and internet-based chlamydia studies. ${ }^{25} 30$ The consumers' reasons for nonparticipation after taking the ECOMPACT testing kit home were also researched. The main hurdle was the process of returning the pathology sample. Women said they were either deterred by the co-ordination required to return their sample to a pathology drop-off site in time, or they simply found it inconvenient to visit a designated pathology site. The data also showed that there was a clear association between whether a consumer chose to participate and the perceived quality of counselling provided by the pharmacist. Significantly more women completed the chlamydia test if they felt that they had received sufficient information about the study from the pharmacist.

\section{Future improvements to ECOMPACT}

To increase the effectiveness of ECOMPACT, we proposed a number of strategies. Professional service payments or incentives alongside ongoing education for pharmacists would increase the pharmacists' skill at counselling and providing information on chlamydia. It could also reduce the likelihood of pharmacists selectively offering the service to some women. Second, providing consumers with convenient options for pathology drop-off sites, investigating the use of dry LVS or urine samples for postal returns, or offering on-site testing at pharmacies, which have private toilet facilities, may increase return rates. Third, the outcomes of referrals of symptomatic women should be followed up. Fourthly, the 'mature-minor' criteria should be investigated to include provision of ECOMACT in the 16-18 year age group. Finally, within pharmacies, there appeared to be a need for more dedicated private consultation areas. While women were comfortable discussing sexual health with the pharmacist, they did not feel comfortable doing so 'over the counter'. The concerns of 'being caught' having a discussion about STIs with a health professional were similar to those identified by Pavlin et $a l^{10}$ in relation to general practice. Therefore, a private consultation area in all pharmacies could alleviate these concerns.

\section{Implication for clinicians and policy makers}

To get tested for chlamydia, consumers currently need to make an appointment to get a pathology request and a follow-up appointment if found positive. Our research has shown that the average pharmacy-based EC consumer was 24 years old and worked fulltime. They may find it difficult or unnecessary to take time off for an appointment, especially if they do not experience any or only mild symptoms. By permitting pharmacists to request a direct-to-consumer pathology test for chlamydia, these consumers can be offered a convenient, 
easier and more accessible option. ECOMPACT was the first study in Australia that enabled pharmacists to do this and required an unprecedented level of participation from them. It also tested the willingness of consumers to embrace and use a new sexual health-related service. Considering that almost half agreed to participate, ECOMPACT has shown that pharmacists could offer chlamydia tests and that their consumers are willing to accept them.

It has been suggested that there be short intense pharmacy-based chlamydia screening interventions in Australia lasting 1 week, two to three times a year. ${ }^{29}$ However, we suggest that a service that is ongoing and available from all pharmacies could have the capacity to increase sexual health awareness, as well as normalise and de-stigmatise chlamydia screening, more so by attaching itself to pharmacy-based EC, which has already become 'normal'. Options of how pathology costs could be funded for a wider rollout of a pharmacy-based chlamydia-screening programme in Australia were discussed in a recently published paper by Currie et al. ${ }^{29}$ We concur with their suggestions that a government funded scheme via the Pharmaceutical or Medicare Benefits Scheme would be feasible, but also propose the alternative option of enabling consumers over the age of 16 years to purchase a chlamydia testing kit as an over-the-counter (OTC) product from a pharmacy. Our research has found that consumers would be willing to purchase a testing kit for around $\$ \mathrm{~A} 26 \pm 9$.

In conclusion, ECOMPACT was found to be simple, effective and acceptable. It enabled community pharmacists to screen consumers, identify and refer those that were symptomatic and request a chlamydia test for those who were not. Its success was defined by its successful integration into a pharmacy setting, the competence and skill by which pharmacists delivered the service and the largely positive feedback from consumers and pharmacists. Given the opportunity, adequate training and support, community pharmacists in Australia are capable of requesting direct-to-consumer chlamydia tests.

Contributors All the authors were responsible for the conception and the design of the study. SG was responsible for project management, data collection, statistical analyses and interpretation of data. SG wrote the first draft of the paper. All authors contributed to and approved the final version of the paper.

Funding This work was supported by the Australian Government Department of Health and Ageing through the Fourth Community Pharmacy Agreement Grants Program and was managed by the Pharmacy Guild of Australia grant number IIG003. The interpretations and conclusions presented here are those of the authors and do not necessarily represent the position of the Pharmacy Guild of Australia. The funding organisation played no role in the design and conduct of the study; collection, management, analysis and interpretation of the data; or preparation, review or approval of the manuscript.

Competing interests None.

Ethics approval Human Research Ethics Committee of the University of Western Australia in Australia.

Provenance and peer review Not commissioned; externally peer reviewed.
Data sharing statement A full report of this study was written and submitted to the Pharmacy Guild of Australia. Available from: http://www.guild.org.au/ sites/The_Guild/tab-Pharmacy_Services_and_Programs/Research_and_ Development/Fourth Agreement/IIG-003.page.

Open Access This is an Open Access article distributed in accordance with the Creative Commons Attribution Non Commercial (CC BY-NC 3.0) license, which permits others to distribute, remix, adapt, build upon this work noncommercially, and license their derivative works on different terms, provided the original work is properly cited and the use is non-commercial. See: http:// creativecommons.org/licenses/by-nc/3.0/

\section{REFERENCES}

1. European Centre for Disease Prevention and Control (ECDPC). Chlamydia Control in Europe. Stockholm: ECDP2009. Published Online First: 4 March 2013. http://www.ecdc.europa.eu/en/ publications/Publications0906_GUI_Chlamydia_Control_in_Europe. pdf

2. Australia's Notifiable Disease Status. Annual Report of the National Notifiable Disease Surveillance System. Australian Government Department of Health and Ageing, 2009.

3. Communicable Diseases Network Australia. National Notifiable Diseases Surveillance System. Published Online First: 10 March 2013. http://www.health.gov.au/nndssdata

4. Peipert JF. Genital Chlamydial Infections. N Engl J Med 2003;349:2424-30.

5. Haggerty CL, Gottlieb SL, Taylor BD, et al. Risk of sequelae after Chlamydia trachomatis genital infection in women. $J$ Infect Dis 2010;201(Suppl 2):S134-55.

6. Land JA, Van Bergen JE, Morre SA, et al. Epidemiology of Chlamydia trachomatis infection in women and the cost-effectiveness of screening. Hum Reprod Update 2010;16:189-204.

7. Risser WL, Risser JM. The incidence of pelvic inflammatory disease in untreated women infected with Chlamydia trachomatis: a structured review. Int J STD AIDS 2007;18:727-31.

8. Harris M, Bennett J, Del Mar C, et al. Guidelines for preventive activities in general practice. The Royal Australian College of General Practitioners, 2009.

9. Kong FYS, Guy RJ, Hocking JS, et al. Australian general practitioner chlamydia testing rates among young people. Med J Australia 2011;194:249-52.

10. Pavlin NL, Gunn JM, Parker R, et al. Implementing chlamydia screening: what do women think? A systematic review of the literature. BMC Public Health 2006;6:221.

11. Rose S, Lawton B, Bromhead C, et al. Self-obtained vaginal swabs for PCR chlamydia testing: a practical alternative. Aust N Z J Obstet Gynaecol 2007;47:415-18.

12. Tilson EC, Sanchez V, Ford CL, et al. Barriers to asymptomatic screening and other STD services for adolescents and young adults: focus group discussions. BMC Public Health 2004;4:21.

13. Anderson $\mathrm{C}$, Thornley T. A pharmacy-based private chlamydia screening programme: results from the first 2 years of screening and treatment. Int J Clin Pharm 2011;33:88-91.

14. Gudka S, Afuwape FE, Wong B, et al. Chlamydia screening interventions from community pharmacies: a systematic review. Sex Health 2013;10:229-39.

15. NCSSG. Looking back, moving forward: Annual report of the National Chlamydia Screening Programme in England 2004/05. London: Department of Health, 2005.

16. LaMontagne DS, Fenton KA, Randall S, et al. Establishing the National Chlamydia Screening Programme in England: results from the first full year of screening. Sex Transm Infect 2004;80:335-41.

17. Baraitser $P$, Pearce V, Holmes $J$, et al. Chlamydia testing in community pharmacies: evaluation of a feasibility pilot in south east London. Qual Saf Health Care 2007;16:303-7.

18. TNS Healthcare. Pharmacy Chlamydia Screening Pathfinder Evaluation (PCSPf). Final. London: Department of Health, 2007.

19. Gudka S, Bourdin A, Watkins K, et al. Self-reported risk factors for chlamydia: a survey of pharmacy-based emergency contraception consumers. Int J Pharm Pract 2013 Published Online First: 29 May 2013. doi:10.1111/ijpp.12042

20. Anderson C, Blenkinsopp A. Community pharmacy supply of emergency hormonal contraception: a structured literature review of international evidence. Hum Reprod 2006;21:272-84.

21. Gudka S, Creagh A, Marshall L, et al. To develop and pilot a best practice community pharmacy chlamydia screening model. Canberra: Pharmacy Guild of Australia, 2009. Contract No.: IIG-003. 
22. Williams H, Tabrizi SN, Lee W, et al. Adolescence and other risk factors for Chlamydia trachomatis genitourinary infection in women in Melbourne, Australia. Sex Transm Infect 2003;79:31-4.

23. Walleser S, Salkeld G, Donovan B. The cost effectiveness of screening for genital Chlamydia trachomatis infection in Australia. Sex Health 2006;3:225-34.

24. Pojski C, Atkin L, Williams H. Review of Sexual Health Clinical Services in Victoria. Family Planning Victoria, 2006.

25. Brabin L, Thomas G, Hopkins M, et al. Delivery of chlamydia screening to young women requesting emergency hormonal contraception at pharmacies in Manchester, UK: a prospective study. BMC Womens Health 2009;9:7.

26. Emmerton L, Buhrer Skinner M, Gardiner E, et al. A trial of the distribution of chlamydia self-collection postal specimen kits from Australian community pharmacies. Sex Health 2011;8:130-2.
27. van Bergen JEAM, Postma MJ, Peerbooms PGH, et al.

Effectiveness and cost-effectiveness of a pharmacy-based screening programme for Chlamydia trachomatis in a high-risk health centre population in Amsterdam using mailed home-collected urine samples. Int J STD AIDS 2004;15:797-802.

28. Bloomfield PJ, Kent C, Campbell D, et al. Community-based chlamydia and gonorrhea screening through the United States mail, San Francisco. Sex Transm Dis 2002;29:294-7.

29. Currie MJ, Deeks LS, Cooper GM, et al. Community pharmacy and cash reward: a winning combination for chlamydia screening? Sex Transm Infect 2013;89:212-16.

30. Greenland KE, Op de Coul EL, van Bergen JE, et al. Acceptability of the internet-based Chlamydia screening implementation in the Netherlands and insights into nonresponse. Sex Transm Dis 2011;38:467-74. 